\title{
Three-dimensional reconstruction of conventional catheter angiography-identified coronary artery aneurysms and ectasias
}

\author{
Jakub Chmiel ${ }^{1} \oplus$, Krzysztof Piotr Malinowski ${ }^{2,3}$, Kacper Miłosz Książek ${ }^{1}$, \\ Grażyna Wnuk ${ }^{1}$, Jagoda Dradrach ${ }^{1}$, Klaudia Proniewska ${ }^{4}$, \\ Łukasz Partyka ${ }^{3}$, Kenneth Rosenfield ${ }^{5}$, Piotr Musiałek ${ }^{1}$ \\ ${ }^{1}$ Department of Cardiac and Vascular Diseases, Jagiellonian University Medical College, \\ John Paul II Hospital, Krakow, Poland \\ ${ }^{2}$ Second Department of Cardiology, Jagiellonian University Medical College, Krakow, Poland \\ ${ }^{3}$ KCRI Angiographic Corelab and Division of Statistics, Krakow, Poland \\ ${ }_{4}^{4}$ Jagiellonian University Medical College, Department of Bioinformatics and Telemedicine, Krakow, Poland \\ ${ }^{5}$ Department of Cardiology, Massachusetts General Hospital, Boston, United States
}

Coronary artery aneurysms and ectasias (CAAE) occur in the course of atherosclerotic or connective tissue/inflammatory disease [1]. Focal dilations $\geq 1.5$ times greater than the adjacent segments' reference diameter $(\mathrm{RD})$ are typically described as an 'aneurysms' (example in Fig. 1A, B), whereas the term 'ectasia' is usually used for diffuse and long-segmental dilations [2].

Coronary artery aneurysms and ectasias are mostly incidental findings of conventional coronary artery angiography (CAG, 1.2-4.9\%) [1]. Some CAAEs occur in relation to coronary stenosis [1]. CAEAs disturb coronary flow and may enhance thrombus formation, serving as a culprit for acute myocardial infarction and sudden cardiac death $[1,3]$. Furthermore, CAAE progressive enlargement may result in its rupture and cardiac tamponade [1]. A significant diagnostic and clinical problem of CAAE [1] starts with the present lack of a standardized definition; an issue largely related to limitations of CAAE characterization using CAG planar images [2]. Indeed, conventional (catheter) CAG characterization of CAAEs may be prone to significant errors $[2,4]$.

In a series of consecutive CAGs in our database [5], we evaluated the feasibility of routine three-dimensional (3D) CAAE characterizations using a commercially available $3 \mathrm{D}$ image angiographic reconstruction system (CAAS Workstation 7.4, Pie Medical Imaging, The Netherlands). The system is semi-automated; it involves identification of the region of interest and delineation of CAAE and reference segments [4]. To enable 3D reconstruction (3DR), the software requires calibration and planar image characteristics including rotation and angulation details [6]. Specifically, a 'green-zone' for 3DR feasibility needs to be established, with the two planes having a difference of at least 30 degrees as a fundamental requirement [6].

Beyond routine CAAE characteristics such as the feeding vessel RD, CAAE mean diameter, maximal diameter and length, several new parameters were evaluated such as the length of CAAE segment, with dilation exceeding the $\mathrm{RD}>1.0$-fold, $>1.5$-fold, and $>2.0$-fold. Measurements were performed with the agreement of two angiographic Corelab analysts.

Out of 20 consecutive CAAE angiograms in the sample, $15(75 \%)$ were suitable for $3 \mathrm{DR}$ as per the software-demanded parameters. The reasons for 3DR unsuitability were as follows: lack of the software 'green-zone' for any of the available

Address for correspondence: Jakub Chmiel, MD and Piotr Musialek, MD, DPhil, Department of Cardiac and Vascular Diseases, Jagiellonian University Medical College, John Paul II Hospital, ul. Prądnicka 80, 31-202 Kraków, Poland, tel: +48 1261422 87, fax: +48 1261433 32, e-mails: jakubandrzejchmiel@gmail.com; pmusialek@szpitaljp2.krakow.pl Received: 28.09.2020 Accepted: 17.01.2021

This article is available in open access under Creative Common Attribution-Non-Commercial-No Derivatives 4.0 International (CC BY-NC-ND 4.0) license, allowing to download articles and share them with others as long as they credit the authors and the publisher, but without permission to change them in any way or use them commercially. 


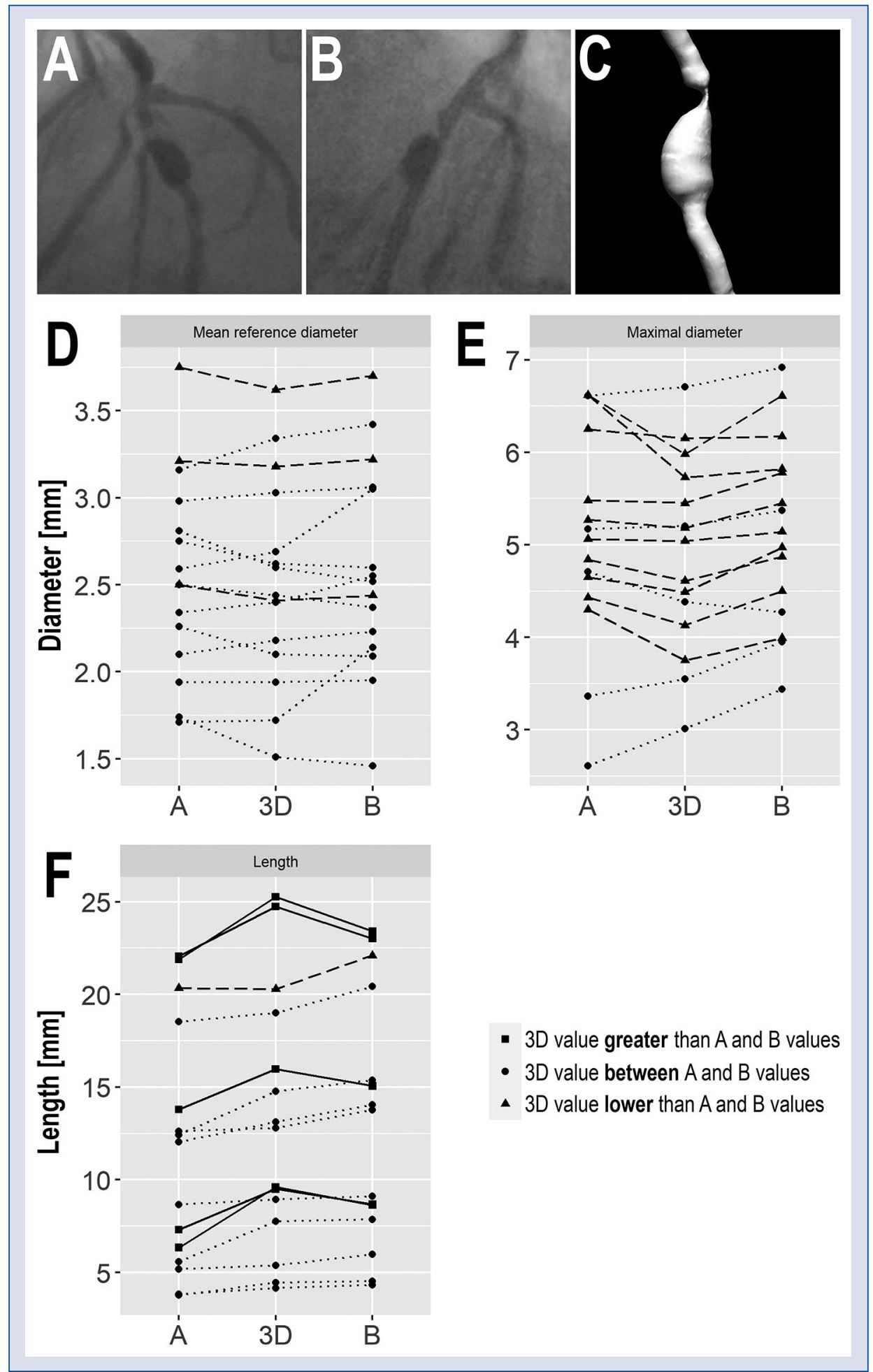

Figure 1. Typical example of coronary artery aneurysms and ectasias (CAAE) raw planar images and three-dimensional (3D) reconstruction (3DR), and the individual data charts for all studied CAAEs; A-C. Typical example of an CAAE two-dimensional (2D) planar images (A, B) and its 3DR (C); D-E. Relations between the 2D and 3D numeric values for CAAE (D) reference diameter, $(\mathbf{E})$ maximal diameter and $(\mathbf{F})$ length.

two-dimensional (2D) projections (3 out of 5 cases), poor recording quality in one of the two required projections ( 1 case) and CAEA overlap with a large branch of another artery in one of the two projections in the 'green' zone ( 1 case). Table 1 shows, for each major coronary segment, suggested projec- 
Table 1. Guideline on two-dimensional angiography projections spatial distribution to enable three-dimensional reconstruction (as per each major coronary segment). According to [6] (modified). Note that per-patient optimal angulations may vary, and an adjustment of the projection(s) may be needed.

\begin{tabular}{lcc}
\hline Coronary artery & Projection 1 & Projection 2 \\
\hline Left main and bifurcation & RAO 20, caudal 40 & RAO 0, caudal 10 \\
Left circumflex artery & LAO 10, caudal 25 & RAO 25, caudal 25 \\
LAD and diagonal(s) & RAO 0, cranial 40 & RAO 30, cranial 15 \\
RCA proximal, RCA mid & LAO 40, caudal 0 & RAO 0, caudal 0 \\
RCA distal & LAO 40, caudal 0 & LAO 30, caudal 30 \\
\hline
\end{tabular}

LAD — left anterior descending artery; LAO — left anterior obilque; RAO — right anterior obilque; RCA — right coronary artery

tions to enable 3DR; these should be considered in prospective data acquisition.

Significant stenoses ( $>50 \%$ of lumen diameter) were present at the proximal end in 6 and distal end in 4 CAAEs, with both in 1 CAAE. One-third CAAEs had a maximal diameter $>2$ times greater than RD. 3DR average values (range) [mm] were as follows: RD 2.52 (1.51-3.62), mean diameter 3.90 (2.45-5.45), maximal diameter 4.89 (3.01-6.71), length 13.05 (4.15-25.27), length of segment dilated > 1 RD 12.10 (3.52-24.01), > 1.5 RD 7.94 (2.31-22.11), and > 2 RD 3.89 (3.25-6.49). The CAAE volume, as obtained via $3 \mathrm{D}$ reconstruction, was $144.86(33-402) \mathrm{mm}^{3}$. The following differences between the $2 \mathrm{D}$ and $3 \mathrm{D}$ parameters [mm] were identified: RD $0.05(0.02-0.09 ; 2.30 \%$; $\mathrm{p}=0.0072)$, mean diameter $0.12(0.01-0.22 ; 2.84 \%$; $\mathrm{p}=0.0312)$, maximal diameter $0.22(0.12-0.32$; $4.19 \% ; \mathrm{p}=0.0004)$, length $-0.69(-1.30--0.08$; $-5.50 \% ; \mathrm{p}=0.0284)$, length offragment dilated $>1 \mathrm{RD}$ $-0.77(-1.32--0.22 ;-7.61 \% ; \mathrm{p}=0.0095),>1.5 \mathrm{RD}$ $-0.22(-0.82--0.38 ; \mathrm{p}=0.4404)$ and $>2 \mathrm{RD}$ $0.08(-0.29-0.14 ; 11.84 \% ; \mathrm{p}=0.4566)$. Individual relations between the $2 \mathrm{D}$ and $3 \mathrm{DR}$ numeric values for CAAE RD, maximal diameter and length are shown in Figure 1.

Principal findings from this work, evaluating performance of an angiographic 3DR software in relation to its application for CAAE characteristics, are the following: (1) CAAE 3DR appears feasible for a majority of CAAEs identified on routine CAG; (2) numeric parameters of 3D-reconstructed CAAEs are not a "simple" mean of those in $2 \mathrm{D}$ projections; and (3) not infrequently ( $>40 \%$, see Fig. 1D-F) the numeric values of $3 \mathrm{D}$ assessment fall outside the 2D planar values (Fig. 1D-F), suggesting potential new information from 3DR. In addition, 3DR enabled evaluation of the CAAE volume; a parameter not available on $2 \mathrm{D}$ projections that may have a prognostic value $[1,2]$. Despite the fact that the $2 \mathrm{D}$ and $3 \mathrm{D}$ parameters appeared significantly correlated, some 3D measurements fell below conventional CAG measurements whereas others fell above (Fig. 1). Thus, on 3DR, CAEAs may tend to appear longer and narrower than on plain 2D projections; an observation that requires further elucidation.

While these findings require confirmation in a larger CAAE series in relation to computed tomography angiography (CTA), their consistency in the present sample of unselected routine angiograms with CAAE suggests that CAAE 3DR based on standard CAG images might provide new information relevant to monitoring the course of the disease and patient risk. Indeed, autopsy data show that CAAEs often have a complex 3D structure whose prior knowledge would have, in a proportion of cases, affected management [2]. Optimizing the methodology of CAAEs qualitative and quantitative evaluation based on routine image acquisition may play a role in both triggering the intervention and selecting the type of intervention (percutaneous vs. surgical) [2]. Stent revascularisation of lesions involving CAAE poses particular difficulties in relation to stent sizing (diameter, length) and the risk (and consequences) of stent malapposition [7]. On the other hand, aneurysm formation may occur as a late complication of (drugeluting in particular) stent use [8].

Computed tomography angiography is today the \#1 tool to obtain CAAE 3D characteristics [4]. CTA, however, it is not performed prior to CAG identification of CAAE but, rather, as a subsequent step in arbitrarily selected cases [9]. Importantly, CTA resolution is $>2$-fold lower than that of $\mathrm{CAG}$ $(\approx 0.5$ vs. $\approx 0.2 \mathrm{~mm})[6,7]$, and CTA is prone to gating-related (increased heart rate, arrhythmias) and calcifications-related artifacts [4]. Further- 
more, CTA following CAG requires another contrast medium dose and X-ray exposure [10]. For these reasons it would be of interest to employ 3D reconstructions as a potential replacement of CTA verification or as a guidance to selective CTA use. This is one of the major issues of interest today $[9,10]$; thus CAAE $3 \mathrm{D}$ reconstruction against CTA in a larger series of patients is required to fully validate this method.

In conclusion, present findings indicate that CAAE 3DR using routinely-acquired planar CAG images may be feasible for a majority of CAAE identified on CAG. In a significant proportion of CAAEs, the numeric values of (both the conventional and novel) CAAE parameters may fall beyond the $2 \mathrm{D}$ projection values. Thus, 3DR may provide information quantitatively (and perhaps prognostically) different from the one based on analysis of standard 2D images.

\section{Acknowledgements}

This work was supported by Jagiellonian University Medical College Research Grant (N-8/2020 to J.C.) and the science fund of the John Paul II Hospital, Krakow, Poland (no. FN/3/2021 to P.M.). J.C., K.M.K., G.W. and J.D. contributed to this project through their research work in the Cardiovascular Diseases and Interventions Student Research Team at the Jagiellonian University Department of Cardiac and Vascular Diseases (Tutor: Piotr Musiałek, MD, DPhil, FESC).

Conflict of interest: None declared

\section{References}

1. Devabhaktuni S, Mercedes A, Diep J, et al. Coronary artery ectasia - a review of current literature. Curr Cardiol Rev. 2016; 12(4): 318-323, doi: 10.2174/1573403×12666160504100159, indexed in Pubmed: 27142049.

2. Kawsara A, Núñez Gil IJ, Alqahtani F, et al. Management of Coronary Artery Aneurysms. JACC Cardiovasc Interv. 2018; 11(13): 1211-1223, doi: 10.1016/j.jcin.2018.02.041, indexed in Pubmed: 29976357.

3. Musiałek P, Tekieli Ł, Pieniazek P, et al. How should I treat a very large thrombus burden in the infarct-related artery in a young patient with an unexplained lower GI tract bleeding? EuroIntervention. 2011; 7(6): 754-5; discussion 756, doi: 10.4244/ EIJV7I6A119, indexed in Pubmed: 21986333.

4. Díaz-Zamudio M, Bacilio-Pérez U, Herrera-Zarza MC, et al. Coronary artery aneurysms and ectasia: role of coronary CT angiography. Radiographics. 2009; 29(7): 1939-1954, doi: 10.1148/ rg.297095048, indexed in Pubmed: 19926755.

5. Chmiel J, Książek MK, Stryszak W, et al. Temporal changes in the pattern of invasive angiography use and its outcome in suspected coronary artery disease: implications for patient management and healthcare resources utilization. Adv Interv Cardiol. 2018; 14(3): 247-257, doi: 10.5114/aic.2018.78327, indexed in Pubmed: 30302100.

6. CAAS Workstation 7.4 User Manual, Pie Medical Imaging, Maastricht, The Netherlands 2011.

7. Dingli P, Gonzalo N, Escaned J, et al. Intravascular ultrasoundguided management of diffuse stenosis. Radcliffe Cardiology. 2018: 1-18, doi: 10.15420/rc.2018.m005.

8. Hong SJ, Kim H, Ahn CM, et al. Coronary artery aneurysm after second-generation drug-eluting stent implantation. Yonsei Med J. 2019; 60(9): 824-831, doi: 10.3349/ymj.2019.60.9.824, indexed in Pubmed: 31433580.

9. Iwańczyk S, Araszkiewicz A, Borger M, et al. Endocan expression correlated with total volume of coronary artery dilation in patients with coronary artery ectasia. Adv Interv Cardiol. 2020; 16(3): 294-299, doi: 10.5114/aic.2020.99264, indexed in Pubmed: 33597994.

10. Adamson PD, Newby DE. Non-invasive imaging of the coronary arteries. Eur Heart J. 2019; 40(29): 2444-2454, doi: 10.1093/ eurheartj/ehy670, indexed in Pubmed: 30388261. 